\title{
Erratum to: Information Security for Global Information Infrastructures
}

\author{
Sihan Qing ${ }^{1}$ and Jan H.P. Eloff ${ }^{2}$ \\ 1 Engineering Research Center for Information Security Technology, \\ Chinese Academy of Sciences, China \\ 2 Rand Afrikaans University, South Africa
}

Erratum to:

Sihan. Qing and Jan. H.P. Eloff (Eds.)

Information Security for Global Information

Infrastructures

DOI: $10.1007 / 978-0-387-35515-3$

The book was inadvertently published with an incorrect name of the copyright holder. The name of the copyright holder for this book is: (c) IFIP International Federation for Information Processing. The book has been updated with the changes.

The updated original online version for this book can be found at DOI: $10.1007 / 978-0-387-35515-3$ 